\title{
Effect of population density on the development of Mesovelia furcata (Mesoveliidae), Microvelia reticulata and Velia caprai (Veliidae) (Heteroptera: Gerromorpha)
}

\author{
TOMÁš DITRICH ${ }^{1,2}$ and MirosLAV PAPÁČEK ${ }^{1}$ \\ ${ }^{1}$ Department of Biology, Faculty of Education, University of South Bohemia, Jeronýmova 10, 37115 České Budějovice, \\ Czech Republic; e-mails: ditom@pf.jcu.cz; papacek@pf.jcu.cz \\ ${ }^{2}$ Department of Ecosystem Biology, Faculty of Science, University of South Bohemia, Branišovská 31, 37005 České Budějovice, \\ Czech Republic
}

\begin{abstract}
Key words. Population density, developmental rate, wing dimorphism, body size, oogenesis, Mesoveliidae, Veliidae, Heteroptera
\end{abstract}
\begin{abstract}
Population density during nymphal development affects body size, developmental rate and wing polymorphism in semiaquatic bugs. Nymphs from crowded habitats grow faster and thus gain an advantage in the later stadia. Rapid development results in smaller body size in several gerrids. Macropterous adults develop more frequently at high population densities in most species, which enables the bugs to leave crowded habitats. Three European widespread species Mesovelia furcata Mulsant \& Rey, 1852 (Mesoveliidae), Microvelia reticulata Burmeister, 1835 and Velia caprai Tamanini, 1947 (Veliidae) were reared individually and simultaneously either at a low or high population density. Duration of postembryonic development, wing morph, body size and length of distal oocyte in females were recorded. High population density accelerates development in Mesovelia furcata and Microvelia reticulata. However, there was no trade-off between developmental rate and body size. Accelerated development without a decrease in body size was probably because maturation was delayed. Individually reared nymphs developed faster than nymphs from communal cohorts. No long-winged Microvelia reticulata specimen developed in any treatment. However, more macropterous individuals developed in high-density treatments in Mesovelia furcata (significant) and Velia caprai (not significant). All the nymphs of the species that were reared individually developed into apterous adults. The results suggest that population density strongly influences the life history of semiaquatic bugs. However, the only commonly shared response seems to be an increase in developmental rate when reared at high population densities. Other traits such as wing dimorphism, body size and rate of oogenesis differ at the species level.
\end{abstract}

\section{INTRODUCTION}

Crowding during nymphal development affects the life history of many insect species. A traditional object of research is the "gregaria phase" that develops in crowded populations of Orthoptera and several other herbivores including blissid bugs, noctuid caterpillars, aphids and planthoppers (see Applebaum \& Heifetz, 1999 for review). Population density strongly influences not only the life of plant feeding species, but also the traits of predaceous semiaquatic bugs (Heteroptera: Gerromorpha). Most gerromorphan bugs live on the surface of water, which is a well-restricted $2 \mathrm{D}$ zone, so their population density is well defined. Non-migratory individuals (e.g. nymphs and flightless adults) usually cannot easily escape from areas where population density is high. The habitat can thus become crowded when the area of water surface decreases during droughts or when the eggs hatch simultaneously. Population density of gerrid nymphs can reach up to several hundreds per $\mathrm{m}^{2}$ in the field (Harada \& Spence, 2000).

Semiaquatic bugs are predators and scavengers, feeding on different arthropods trapped in the surface film of water. Almost all temperate species exhibit wing polymorphism. Most species have macropterous, brachypterous / micropterous and apterous morphs (Andersen,
1982). Incidence of the different wing morphs depends on genetic background and/or environmental conditions during nymphal development (Spence \& Andersen, 1994). Vepsäläinen (1973) has proposed a general model for the family Gerridae, which predicts a higher proportion of macropterous individuals in ephemeral and temporary habitats.

One of the main factors affecting the rate of development and flight capability is probably population density. Nymphs that are crowded should have a faster rate of development and proportionally more of them should develop into macropterous adults, which are capable of dispersing. However, the responses of various species reared at high vs. low population densities differ. As in most insect species (Applebaum \& Heifetz, 1999) more long winged (LW) individuals develop at high population densities in Aquarius paludum (Gerridae) (Harada et al., 1997), Microvelia douglasi, Microvelia horvathi and Microvelia kyushuensis (Veliidae) (Muraji et al., 1989; Muraji \& Nakasuji, 1988). On the other hand, proportionally more micropterous specimens develop at high population densities in species such as Gerris buenoi (Harada \& Spence, 2000). Gerris pingreenensis exhibits no or little effect of population density on wing morph development and nymphal duration (Harada \& Spence, 2000). At high nymphal population densities the duration of nym- 
phal development decreases in all gerrids tested (Harada, 1996; Harada \& Spence, 2000; Harada et al., 1997). More rapid postembryonic development is advantageous when intraspecific competition is intense.

Nymphal population density during development also influences body size and the physiological characteristics of the adults. This effect can be sex dependent. When $G$. buenoi and $G$. pingreenensis were reared at a low population density, females were larger than those reared at a high population density, but not in the case of males where there was no significant effect (Harada \& Spence, 2000). Females of $A$. paludum reared at a high population density have a longer preoviposition period than those reared at low population density, but other gerrids do not show this response (Harada \& Spence, 2000; Harada et al., 1997). Apparently, the response to different population densities experienced during development, expressed in terms of wing polymorphism, adult body size and predisposition to reproduce, varies among Gerridae.

This research is focused on the effect of nymphal population density (treatments: isolated nymphs and nymphs reared at low and high population densities) on wing polymorphism, body size and rate of gametogenesis in three common and widely distributed temperate Old World non-gerrid species of semiaquatic bugs, Mesovelia furcata, Microvelia reticulata and Velia caprai. These species differ in their habitat preference, body size, life history traits (Saulich \& Musolin, 2007) and phylogenetical positions (relatedness) (Damgaard, 2008a, b).

\section{MATERIAL AND METHODS}

\section{Terminology, abbreviations and species studied}

Following abbreviations are used in the text: LW - longwinged, macroptery, macropterous; SW - short-winged, brachyptery, brachypterous; WL - wingless, aptery, apterous. Mes. - Mesovelia, Micr. - Microvelia. Last-mentioned abbreviations are used instead of the more commonly used generic name abbreviation " $M$." for both genera, in order to more clearly differentiate between the species.

Three common European semiaquatic bugs, Mesovelia furcata Mulsant \& Rey, 1852 (Mesoveliidae: Mesoveliinae), Microvelia reticulata Burmeister, 1835 (Veliidae: Microveliinae) and Velia caprai Tamanini, 1947 (Veliidae: Veliinae) were used in the experiments. All species have LW and WL morphs, but LW specimens are very rare or absent in Central Europe populations (Ditrich et al., 2008; Mielewczyk, 1980; Papáček \& Jandová, 2003; Wróblewski, 1980; Zimmermann, 1984). However, the percentage of LW specimens can reach $16 \%$ in some Swedish populations of $V$. caprai (Brönmark et al., 1985)

Mes. furcata and Micr. reticulata have a Palaearctic distribution. These species are mostly trivoltine in Central Europe. Mes. furcata overwinters exclusively in the egg stage (Zimmermann, 1984) and Micr. reticulata in the adult stage. V. caprai occur only in Europe and is uni- or partially bivoltine with a very variable phenology (Ditrich \& Papáček, 2009b; Papáček \& Jandová, 2003). This species can overwinter as an egg or an adult (Ditrich \& Papáček, 2009b). Micr. reticulata and V. caprai develop through five nymphal instars as do most Heteroptera, whereas Mes. furcata has only four instars (Andersen, 1982; Zimmermann, 1984).

\section{Culture conditions}

Three different series of aquaria, all $10 \mathrm{~cm}$ high and filled to a depth of $2 \mathrm{~cm}$ with water were used for the communal rearing of nymphs: $10 \times 15 \mathrm{~cm}$ for Mes. furcata, $10 \times 12 \mathrm{~cm}$ for Micr. reticulata and $15 \times 20 \mathrm{~cm}$ for $V$. caprai.

High and low population density groups were established with 60 and 10 nymphs, respectively. The high-density groups thus corresponded to 50,40 and 20 individuals $/ 100 \mathrm{~cm}^{2}$, respectively. There were ten replicates of every low population density treatment and two of the high population density treatments.

For the individual treatments, $1^{\text {st }}$ instar individuals of Micr. reticulata and Mes. furcata were placed singly into $6 \times 5 \mathrm{~cm}$ plastic containers and $V$. caprai into $8 \times 6 \mathrm{~cm}$ containers. All containers were filled to a depth of $1 \mathrm{~cm}$ with tap water. There were forty-eight replicates of this treatment for each of the three species. All experiments were carried out at a constant temperature $19 \pm 1{ }^{\circ} \mathrm{C}$ and under a long-day photoperiod of $16 \mathrm{~L}$ : 8D. Several pieces of polystyrene were placed in every aquarium as resting sites.

Specimens in all groups were fed frozen Drosophila melanogaster daily as follows: Micr. reticulata: 0.5 flies per $1^{\text {st }}$ instar nymph; 1 fly per $2^{\text {nd }}$ and $3^{\text {rd }}$ instar and 2 flies per $4^{\text {th }}$ and $5^{\text {th }}$ instar; Mes. furcata: 1 fly per $1^{\text {st }}$ and $2^{\text {nd }}$ instar nymph, 2 flies per $3^{\text {rd }}$ instar and 3 flies per $4^{\text {th }}$ instar and $V$. caprai: 1 fly per $1^{\text {st }}$ instar nymph and up to 5 flies per $5^{\text {th }}$ instar nymph.

The aquaria were checked every day between 11 a.m. and 1 p.m., flies were replaced with fresh ones, exuviae and dead nymphs removed. Water was changed every second day. Adults were removed immediately they developed and placed into Bouin's fixative.

\section{Source of nymphs}

Overwintered adults of Micr. reticulata (60 WL specimens) were collected during May 2008 at three ponds in South Bohemia (Motovidlo pond, GPS $48^{\circ} 59^{\prime} 58^{\prime \prime} \mathrm{N}, 1^{\circ} 22^{\prime} 52^{\prime \prime} \mathrm{E}$; Jarval pond, $48^{\circ} 59^{\prime} 30^{\prime \prime} \mathrm{N}, 14^{\circ} 32^{\prime} 51^{\prime \prime} \mathrm{E}$ and Jizba pond, $48^{\circ} 52^{\prime} 50^{\prime \prime} \mathrm{N}, 14^{\circ} 26^{\prime} 22^{\prime \prime} \mathrm{E}$ ) and reared at $24 \pm 2^{\circ} \mathrm{C}$ under a natural photoperiod. All adults were kept in an aquarium $(30 \times 20 \mathrm{~cm})$ filled to a depth of $2 \mathrm{~cm}$ with water, with several pieces of polystyrene as oviposition sites. Any eggs laid were removed daily and placed in an empty aquarium. Only nymphs that hatched within $12 \mathrm{~h}$ of one another were placed as a group in one aquarium.

Females of $V$. caprai do not lay eggs in the laboratory. However, sufficient numbers of overwintering eggs of $V$. caprai were found. First instar nymphs were also collected from several streams in the Novohradské Hory Mts (within $3 \mathrm{~km}$ of $\left.48^{\circ} 37^{\prime} 44^{\prime \prime} \mathrm{N}, 14^{\circ} 39^{\prime} 20^{\prime \prime} \mathrm{E}\right)$ and Rudolfovský Potok stream $\left(48^{\circ} 59^{\prime} 29^{\prime \prime} \mathrm{N}, 14^{\circ} 33^{\prime} 5^{\prime \prime} \mathrm{E}\right)$ in May and June 2008. Only nymphs collected on the same day were placed as a group in one aquarium.

No eggs of Mes. furcata were found at supposed overwintering sites. Thus, first instar nymphs were collected together with Micr. reticulata adults and those caught on any one day were used in the experiment.

All the collecting sites of all the species were sampled again in early July (when the first generation adults was likely to occur) and the wing morph of the adults checked. The data from all sampling sites were pooled for every species.

\section{Features measured and statistical analyses}

Mortality in every instar was evaluated as the percentage of the number entering an instar that died during the instar. Cause of death was scored as ecdysis or unknown. The former was used if a nymph died during ecdysis (old cuticle still attached to its body) or if it was found dead with a pale, soft cuticle 
TABLE 1 . The mortality of Mes. furcata, Micr. reticulata and $V$. caprai was significantly affected by nymphal stage and treatment. The mortality at particular population densities differs significantly in Micr. reticulata and Mes. furcata, non-significantly in $V$. caprai. Mortality among nymphal instars differed significantly in Mes. furcata and $V$. caprai, non-significantly in Micr. reticulata (see text for results of statistical tests). $\mathrm{N}$ - number of individuals entering each stage that successfully moulted; Ent. - number of last instar nymphs that underwent the imaginal ecdysis; Out - number that successfully moulted to adults; $\mathrm{m}-\mathrm{mortality}_{\mathrm{rate}} \mathrm{m}_{\mathrm{e}}-$ mortality during ecdysis; low, high, indiv - low population density, high population density treatment and individually reared specimens.

\begin{tabular}{|c|c|c|c|c|c|c|c|c|c|c|}
\hline \multirow[b]{2}{*}{ Stage } & \multirow[b]{2}{*}{ Variable } & \multicolumn{3}{|c|}{ Mesovelia furcata } & \multicolumn{3}{|c|}{ Microvelia reticulata } & \multicolumn{3}{|c|}{ Velia caprai } \\
\hline & & indiv & low & high & indiv & low & high & indiv & low & high \\
\hline \multirow{3}{*}{ L1 } & $\mathrm{N}$ & 48 & 100 & 120 & 48 & 100 & 120 & 48 & 100 & 120 \\
\hline & $\mathrm{m}$ & $12.5 \%$ & $0 \%$ & $4.2 \%$ & $4.2 \%$ & $9 \%$ & $5.8 \%$ & $0 \%$ & $8 \%$ & $6.7 \%$ \\
\hline & $\mathrm{m}_{\mathrm{e}}$ & - & - & - & - & - & - & - & - & - \\
\hline \multirow{3}{*}{ L2 } & $\mathrm{N}$ & 42 & 100 & 115 & 46 & 91 & 113 & 48 & 92 & 112 \\
\hline & $\mathrm{m}$ & $4.8 \%$ & $13 \%$ & $15.7 \%$ & $0 \%$ & $4.4 \%$ & $3.5 \%$ & $0 \%$ & $5.4 \%$ & $4.5 \%$ \\
\hline & $\mathrm{m}_{\mathrm{e}}$ & $2.4 \%$ & $3 \%$ & $3.5 \%$ & $0 \%$ & $0 \%$ & $0 \%$ & $0 \%$ & $0 \%$ & $3.6 \%$ \\
\hline \multirow{3}{*}{ L3 } & $\mathrm{N}$ & 40 & 87 & 97 & 46 & 87 & 109 & 48 & 87 & 107 \\
\hline & $\mathrm{m}$ & $5 \%$ & $6.9 \%$ & $7.2 \%$ & $2.2 \%$ & $6.9 \%$ & $0 \%$ & $2.1 \%$ & $6.9 \%$ & $5.6 \%$ \\
\hline & $\mathrm{m}_{\mathrm{e}}$ & $2.5 \%$ & $2.3 \%$ & $3.1 \%$ & $0 \%$ & $2.3 \%$ & $0 \%$ & $0 \%$ & $1.1 \%$ & $1.9 \%$ \\
\hline \multirow{3}{*}{ L4 } & $\mathrm{N}$ & 38 & 81 & 90 & 45 & 81 & 109 & 47 & 81 & 101 \\
\hline & $\mathrm{m}$ & $0 \%$ & $21 \%$ & $72.2 \%$ & $0 \%$ & $6.2 \%$ & $0 \%$ & $44.7 \%$ & $34.6 \%$ & $29.7 \%$ \\
\hline & $\mathrm{m}_{\mathrm{e}}$ & $0 \%$ & $2.5 \%$ & $3.3 \%$ & $0 \%$ & $1.2 \%$ & $0 \%$ & $0 \%$ & $11.1 \%$ & $8.9 \%$ \\
\hline \multirow{3}{*}{ L5 } & $\mathrm{N}$ & - & - & - & 45 & 76 & 109 & 26 & 53 & 71 \\
\hline & $\mathrm{m}$ & - & - & - & $0 \%$ & $13.2 \%$ & $0 \%$ & $73.1 \%$ & $75.5 \%$ & $84.5 \%$ \\
\hline & $\mathrm{m}_{\mathrm{e}}$ & - & - & - & $0 \%$ & $0 \%$ & $0 \%$ & $53.8 \%$ & $62.3 \%$ & $73.2 \%$ \\
\hline \multirow{2}{*}{$\begin{array}{l}\text { Imaginal } \\
\text { Ecdysis }\end{array}$} & Ent. & 38 & 64 & 25 & 45 & 66 & 109 & 7 & 13 & 11 \\
\hline & me & $0 \%$ & $6.3 \%$ & $0 \%$ & $0 \%$ & $0 \%$ & $0.9 \%$ & $14.3 \%$ & $15.4 \%$ & $27.3 \%$ \\
\hline \multirow{4}{*}{ Overall } & $\mathrm{N}$ & 48 & 100 & 120 & 48 & 100 & 120 & 48 & 100 & 120 \\
\hline & $\mathrm{m}$ & $20.8 \%$ & $40 \%$ & $79.2 \%$ & $6.3 \%$ & $34 \%$ & $10 \%$ & $87.5 \%$ & $89 \%$ & $93.3 \%$ \\
\hline & $\mathrm{m}_{\mathrm{e}}$ & $4.2 \%$ & $11 \%$ & $8.3 \%$ & $0 \%$ & $3 \%$ & $0.8 \%$ & $31.3 \%$ & $45 \%$ & $58.3 \%$ \\
\hline & Out & 38 & 60 & 25 & 45 & 66 & 108 & 6 & 11 & 8 \\
\hline
\end{tabular}

(probably attacked during moulting by other nymphs). Nymphs that died during moulting were recorded as having died in the next instar. Mortality during ecdysis was evaluated as the percentage of the individuals undergoing ecdysis (see above) that died during ecdysis.

The duration of nymphal development of Micr. reticulata is the average number of days that elapsed between hatching and the imaginal ecdysis for all the individuals. However, the dates on which the eggs of Mes. furcata and $V$. caprai hatched are unknown. Thus, the duration of development of these species was defined as the number of days from the first ecdysis (into second instar) to the imaginal ecdysis for specimens in each treatment. As it was impossible to follow up individuals in the low and high-density population treatments, the duration of nymphal development in these groups was evaluated as the number of days from the mean date of the first ecdysis to that of imaginal ecdysis in every treatment.

Wing morph recorded for adults and nymphs that died during the last nymphal instar / during ecdysis to the last nymphal instar, was determined by examining their wing pads, which can easily be seen. Sex of adults and individuals that died during the imaginal ecdysis was recorded.

Selected morphometric characters of the specimens reared in the different treatments were measured and compared: medial body length, interocular width, length of left femora of all three pairs of legs and, in females, length of the most distal oocyte. These parameters were measured under a microscope for every successfully ecdysed adult specimen. Medial body length and interocular width are generally good indicators of body size in insects. Lengths of femora were examined because both increased body size and/or prolonged legs can probably increase foraging activity and prey capture success in semiaquatic bugs. Both these parameters (body size and leg length) were measured, because they are not necessarily well correlated and the body size of an individual may change during adult life (see Andersen, 1982; Taylor \& McPherson, 1999). Length of distal oocyte was used as an indirect indicator of female maturation and rate of oogenesis.

The proportion of WL specimens and the sex ratio in the different treatments was compared using contingency tables; differences in mortality in the treatments and different nymphal instars were tested using three-dimensional contingency tables. Duration of nymphal development, body parameters and length of distal oocyte among treatments and between sexes were compared using one-way ANOVA and t-tests (assuming equal variance), respectively. Post-hoc Tukey's multiple comparison was used when ANOVAs revealed significant differences. The level of significance was set as $\alpha=0.05$. All tests were carried out using software Statistica 7.0 (Statsoft, Tulsa, OK).

\section{RESULTS}

\section{Mortality}

The incidence of mortality was significantly associated with both the treatment and nymphal stage in all the species (all $P<10^{-3}$ ). The overall mortality was highest in $V$. caprai (Pearson $\chi_{2}^{2}=0.58, P=0.75$ ), followed by Mes. furcata and Micr. reticulata (Table 1). The effect of density on mortality was only significant in the latter two species (Pearson $\chi_{2}^{2}=37.85, P<10^{-6}$; Pearson $\chi_{2}^{2}=$ 


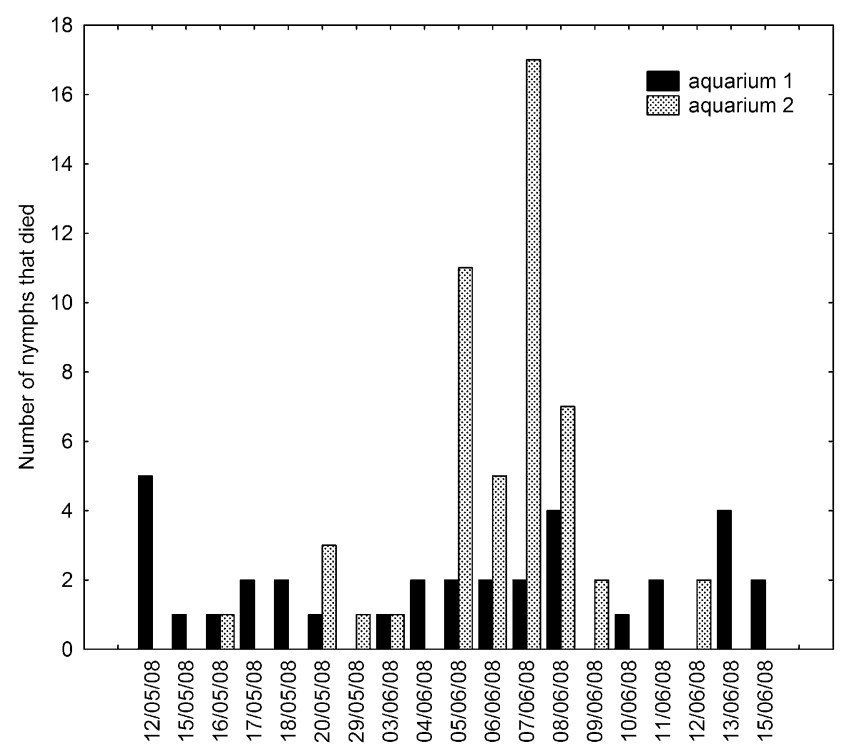

Fig. 1. Mortality of Mesovelia furcata nymphs recorded at 1 to 4 day intervals, excluding those that died during moulting, in both high population density treatment aquaria. Whereas mortality in aquarium 1 is regular it increased rapidly over a period of four days in aquarium 2 .

27.41, $P<10^{-5}$; respectively). Mortality in Micr. reticulata was highest in the low population density treatment, followed by high population density and individually reared nymphs. Mortality of Mes. furcata nymphs was similar at both high and low population densities (see Table 1).

Mortality among instars differed significantly in Mes. furcata (Pearson $\chi_{3}^{2}=136.34, P<10^{-5}$ ) and $V$. caprai (Pearson $\chi_{4}^{2}=452.59, P<10^{-5}$ ). The highest mortality was observed in fourth and fifth instars (see Table 1). No significant difference in mortality was found among instars of Micr. reticulata (Pearson $\chi^{2}{ }_{4}=8.71, P=$ 0.069).

Mortality did not differ significantly among aquaria within treatments in all species (all $P>0.13$ except in the high population density treatment of Mes. furcata with $\chi^{2}{ }_{1}$ $=3.8, P=0.051)$. Because the mortality of Mes. furcata in the high population density treatment was only margin- ally significant, the distribution of mortality of nymphs (only those that died of unknown causes) in both high population density aquaria was checked. There was high nymphal mortality over a period four consecutive days in aquarium 2 (see Fig. 1).

The incidence of mortality at ecdysis was not significantly associated with either population density or nymphal stage in Mes. furcata (Pearson $\chi^{2}{ }_{17}=35.13, P=$ 0.06 ) and Micr. reticulata (Pearson $\chi_{22}^{2}=21.84, P=$ 0.47). This effect was significant only in $V$. caprai (Pearson $\chi_{22}^{2}=420.61, P<10^{-5}$ ) with the highest mortality at ecdysis occurring in the high population density treatment and during the moult to the fifth nymphal instar (Table 1). Both treatment (Pearson $\chi_{2}^{2}=7.89, P=0.02$ ) and nymphal stage (Pearson $\chi^{2}{ }_{4}=400.05, P<10^{-5}$ ) had a significant effect on mortality. Nymphs that died during ecdysis usually died while moulting with the old cuticle still attached to their body, often with only ecdysial suture ruptured.

\section{Wing morphs}

Adults and fifth instar nymphs of Micr. reticulata were WL in all treatments. On the other hand the frequencies of the LW and SW morphs of Mes. furcata varied across treatments: all the individually reared nymphs developed into WL adults, and only four individuals (4.9\%) reared at a low population density were LW. Most winged individuals of Mes. furcata developed in the high population density group: $16 \mathrm{LW} \mathrm{(17.8 \% )} \mathrm{and} \mathrm{two} \mathrm{SW} \mathrm{bugs} \mathrm{(2.2 \% )}$ (see Table 2). The effect of nymphal population density on wing polymorphism in Mes. furcata was significant (Pearson $\chi_{2}^{2}=12.78, P=0.0017$ ). No winged morphs occurred among the $V$. caprai reared individually and at low population densities. However, three fifth instar nymphs $(4.2 \%)$ with distinct wing pads, indicating LW morphs, were present in the high population density group. The effect of nymphal population density on $V$. caprai wing dimorphism was not significant (Pearson $\chi_{2}^{2}$ $=3.23, P=0.199$ ).

No winged specimens of Mes. furcata or $V$. caprai were found at the collecting sites $(\mathrm{N}=124$ and 162 adults and last instar nymphs, respectively), whereas $4.2 \%$ of the

TABLE 2. Sex ratio, wing morph and duration of nymphal development in Mes. furcata, Micr. reticulata and V. caprai reared at different population densities. N - number of individuals; low, high, indiv - low population density, high population density treatments and individually reared bugs; WL - wingless (apterous), SW - short-winged, LW - long-winged. Mean and SD of duration of nymphal development in days.

\begin{tabular}{|c|c|c|c|c|c|c|c|c|c|c|}
\hline \multirow{2}{*}{$\begin{array}{l}\text { Species } \\
\text { Treatment }\end{array}$} & & \multicolumn{3}{|c|}{ Mesovelia furcata } & \multicolumn{3}{|c|}{ Microvelia reticulata } & \multicolumn{3}{|c|}{ Velia caprai } \\
\hline & & indiv & low & high & indiv & low & high & indiv & low & high \\
\hline $\mathrm{N}$ of initial L1 nymphs & & 48 & 100 & 120 & 48 & 100 & 120 & 48 & 100 & 120 \\
\hline \multirow{3}{*}{$\begin{array}{l}\text { Adults (including those } \\
\text { that died during imaginal } \\
\text { ecdysis) }\end{array}$} & total $\mathrm{N}$ & 38 & 64 & 25 & 45 & 66 & 109 & 7 & 13 & 11 \\
\hline & Females & 20 & 35 & 8 & 24 & 27 & 55 & 4 & 8 & 6 \\
\hline & Males & 18 & 29 & 17 & 21 & 39 & 54 & 3 & 5 & 5 \\
\hline \multirow{3}{*}{$\begin{array}{l}\text { Morph of adults and } \\
\text { last nymphal instar }\end{array}$} & WL & 38 & 77 & 72 & 45 & 76 & 109 & 26 & 53 & 68 \\
\hline & SW & 0 & 0 & 2 & 0 & 0 & 0 & 0 & 0 & 0 \\
\hline & LW & 0 & 4 & 16 & 0 & 0 & 0 & 0 & 0 & 3 \\
\hline \multirow{2}{*}{$\begin{array}{l}\text { Duration of nymphal } \\
\text { development in days }\end{array}$} & Mean & 20.84 & 24.11 & 21.96 & 30.13 & 35.94 & 34.6 & 25.14 & 24.69 & 25.27 \\
\hline & SD & 1.05 & 2.85 & 2.85 & 2.15 & 4.15 & 3.71 & 1.57 & 1.11 & 1.79 \\
\hline
\end{tabular}



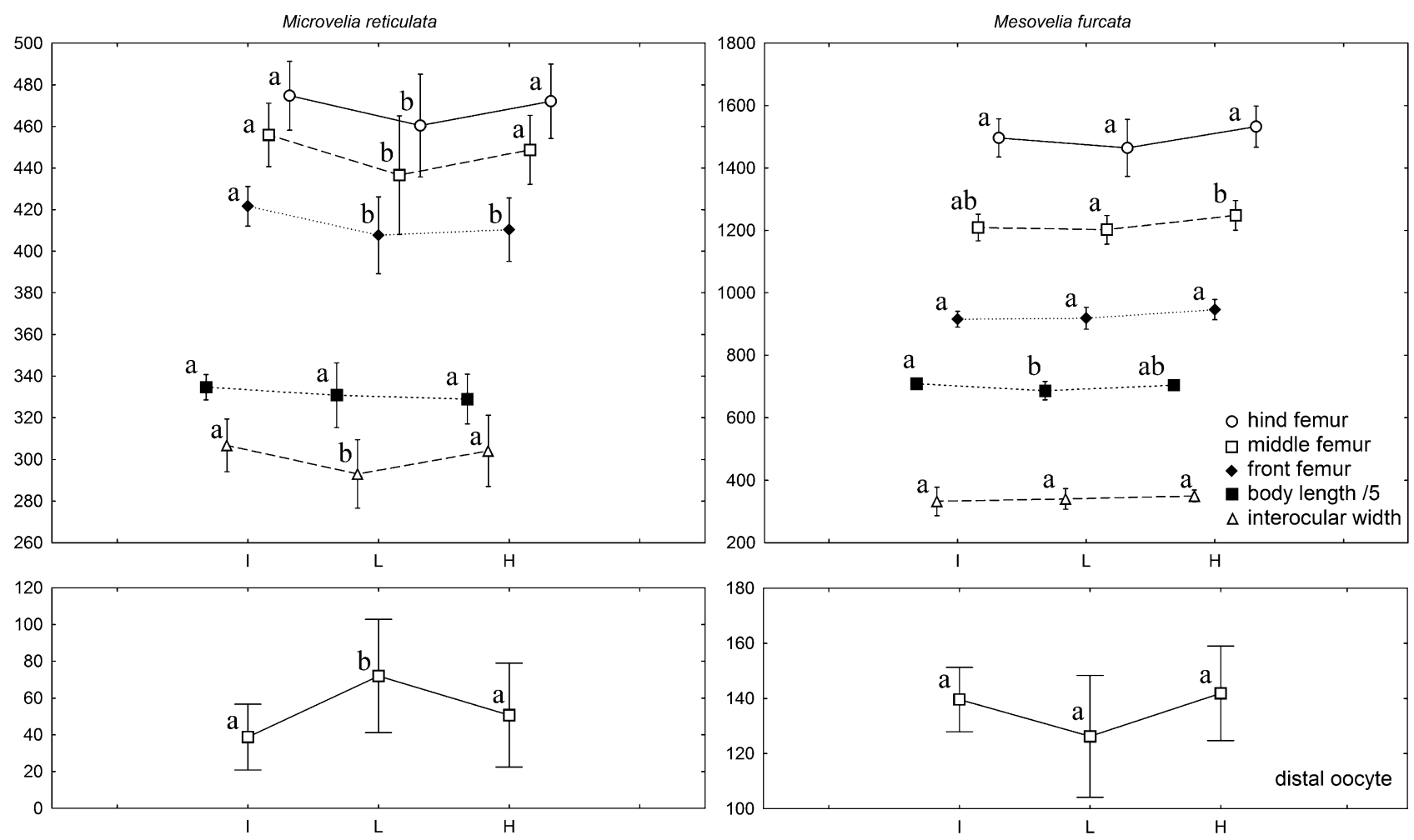

Fig. 2. Means (centroids) and standard deviations (vertical bars) of particular characteristics of the females of Mesovelia furcata and Microvelia reticulata that developed at different nymphal population densities. All differences between females of Micr. reticulata reared at low vs. high population densities were significant, except for medial body length. In Mes. furcata the differences in body length, length of distal oocyte and length of middle femur were significant. Differences in the other femoral lengths were marginally significant (one-way ANOVA, see Table 3). Same symbols with different letters differ significantly ( $p<0.05$, Tukey test). All measurements are in $\mu \mathrm{m}$ and body length is divided by 5 . I - individual rearing; $\mathrm{L}$ - low density; $\mathrm{H}$ - high density treatment.

Micr. reticulata caught in the field $(\mathrm{N}=143)$ were $\mathrm{LW}$, the rest WL.

\section{Sex ratio}

The sex ratio of newly emerged adults was not affected significantly by the population density at which the nymphs were reared in any of the species (Pearson $\chi_{2}^{2}=$ $3.9, P=0.14$ for Mes. furcata; Pearson $\chi_{2}^{2}=2.1, P=$ 0.35 for Micr. reticulata and Pearson $\chi_{2}^{2}=0.12, P=0.94$ for $V$. caprai) (Table 2).

\section{Duration of nymphal development}

As the development times of males and females did not differ in any of the species (t-test; $\mathrm{t}_{125}=-1.1, P=0.27$ for Mes. furcata; $\mathrm{t}_{218}=-1.67, P=0.1$ for Micr. reticulata; $\mathrm{t}_{29}$ $=-0.25, P=0.81$ for $V$. caprai) the data for both sexes were pooled.

The duration of nymphal development (from the first nymphal instar to imaginal ecdysis, see Materials and methods) differed significantly among treatments for Mes. furcata (one-way ANOVA; $\mathrm{F}_{2,124}=22.6 ; P<10^{-5}$ ).

TABLE 3. Influence of nymphal population density (low vs. high vs. individual) on certain adult characteristics of Mes. furcata and Micr. reticulata. Results are for a one-way ANOVA. Significant results $(\alpha=0.05)$ are marked with an asterisk. Bl - body length; Iow - interocular width; ff, $\mathrm{mf}, \mathrm{hf}$ - length of front, middle and hind femur; do - length of longest distal oocyte. Note: some body parts of several specimens were not measured because they were damaged. Distal oocyte of 60 adult females of Micr. reticulata (20 from each treatment) and 50 of Mes. furcata (18 from individual, 24 from low and 8 from the high population density treatment) were measured.

\begin{tabular}{|c|c|c|c|c|c|c|c|c|c|c|c|c|}
\hline & \multicolumn{6}{|c|}{ Microvelia reticulata } & \multicolumn{6}{|c|}{ Mesovelia furcata } \\
\hline & \multicolumn{3}{|c|}{ Females } & \multicolumn{3}{|c|}{ males } & \multicolumn{3}{|c|}{ females } & \multicolumn{3}{|c|}{ males } \\
\hline & $\mathrm{F}$ & d.f. & $\mathrm{P}$ & $\mathrm{F}$ & d.f. & $\mathrm{P}$ & $\mathrm{F}$ & d.f. & $\mathrm{P}$ & $\mathrm{F}$ & d.f. & $P$ \\
\hline $\mathrm{B} 1$ & 1.75 & 2,103 & 0.18 & 2.53 & 2,106 & 0.09 & 5.32 & 2,59 & $<10^{-5 *}$ & 5.3 & 2,56 & $0.008^{*}$ \\
\hline Iow & 6.11 & 2,104 & $0.003 *$ & 0.84 & 2,106 & 0.44 & 0.704 & 2,59 & 0.5 & 0.606 & 2,56 & 0.55 \\
\hline ff & 6.10 & 2,104 & $0.003 *$ & 0.96 & 2,101 & 0.39 & 2.89 & 2,59 & 0.06 & 0.42 & 2,56 & 0.66 \\
\hline $\mathrm{mf}$ & 6.30 & 2,104 & $0.003 *$ & 6.34 & 2,103 & $0.003^{*}$ & 3.43 & 2,59 & $0.04 *$ & 0.77 & 2,56 & 0.47 \\
\hline hf & 4.46 & 2,104 & $0.01 *$ & 2.94 & 2,103 & 0.06 & 2.75 & 2,59 & 0.07 & 2.64 & 2,56 & 0.08 \\
\hline do & 8.197 & 2,57 & $0.0007 *$ & & & & 3.76 & 2,47 & $0.03 *$ & & & \\
\hline
\end{tabular}


It was longest at the low population density, shorter at the high population density and shortest when the nymphs were reared individually (see Table 2). Post-hoc Tukey's multiple comparison showed significant differences between the low vs. high $\left(P<10^{-3}\right)$ and low vs. individual $\left(P<10^{-4}\right)$ treatments, but non-significant difference between high vs. individual treatment $(P=$ 0.18). The duration of nymphal development from eclosion to imaginal ecdysis in Micr. reticulata was also affected significantly by treatment (one-way ANOVA; $\mathrm{F}_{2,217}=36.93 ; P<10^{-5}$ ) with the same pattern as in Mes. furcata (see Table 2). Post-hoc Tukey's multiple comparison revealed significant difference between all treatments (low vs. high $P=0.04$; low vs. individual $P<$ $10^{-4}$; high vs. individual $P<10^{-4}$ ). The population density at which the nymphs were reared had no significant effect on the duration of development in $V$. caprai (one-way ANOVA; $\mathrm{F}_{2,28}=0.5 ; P=0.61$ ).

\section{Body size and maturation of the ovaries}

Because only a few adults of $V$. caprai successfully moulted $(\mathrm{N}=25)$, measurements of this species were not analyzed. T-test revealed significant difference in adult body size of the sexes in Mes. furcata and Micr. reticulata. Females of these species were bigger than the males (t-test; $\mathrm{t}_{119}=13.69, P<10^{-6}$ and $\mathrm{t}_{213}=18.46, P<10^{-6}$; respectively). Thus, the data for males and females of these species were analyzed separately. Sizes of the body parts of males were only slightly affected by the population density at which the nymphs were reared: the only significant effects were on the length of the middle femur of Micr. reticulata and body length of Mes. furcata (see Table 3). All the size characteristics of Micr. reticulata females differed significantly among treatments, except body length. Body length of Mes. furcata females was affected significantly and the differences in lengths of the femora length were marginally significant (see Table 3). Females of both these species reared in the low population density treatment were usually the smallest (see Fig. 2 ). Length of distal oocyte differed significantly among females reared in the different treatments in both species (Table 3). However, responses to density differed between these species. Micr. reticulata females reared at the low population density had the longest distal oocyte and in Mes. furcata the smallest (Fig. 2).

\section{DISCUSSION}

\section{Mortality}

The highest total mortality occurred during the last instar of Mes. furcata reared at a high population density. However, most of the nymphs died in one replicate within a very short interval of time most likely due to an infection.

The significantly higher mortality of Micr. reticulata reared at a low population density compared to other treatments is surprising. However, Harada et al. (1997) record the same pattern of mortality in A. paludum. This phenomenon might be an Allee effect (see Stephens et al., 1999) the mechanism of which is unknown, which results in a lower mortality when nymphs are reared at high population densities.

The mortality recorded at ecdysis, especially that which occurs during the moult to the adult stage, is extremely high in $V$. caprai. It was not due to cannibalism because a similar level of mortality was recorded for individually reared nymphs. Moulting of fourth instar nymphs is frequently unsuccessful when individuals are reared at temperatures close to $20^{\circ} \mathrm{C}$ (T. Ditrich, unpubl. data). It may be due to the relatively rapid development of individuals that are less than eight $\mathrm{mm}$ in length. Micr. reticulata smaller than $2 \mathrm{~mm}$ grow slowly. Similarly, Mes. furcata with body sizes up to $3.5 \mathrm{~mm}$ need almost the same amount of time to complete their development as $V$. caprai when reared under the same conditions, even though they go through only just four nymphal instars (Table 2). In addition, there was considerably more adipose tissue in newly ecdysed laboratory reared adults of $V$. caprai than in teneral adults caught in the field. It is possible that all the specimens reared in the laboratory were overfed and bloated due to their greatly enlarged fat body, which greatly reduced the flexibility of their exoskeleton and resulted in many of them dying during ecdysis.

\section{Duration of nymphal development}

Population density did not affect the duration of development in $V$. caprai significantly, possibly because of the small sample size. On the other hand, in both Mes. furcata and Micr. reticulata, as predicted the duration of nymphal development was shorter at high than at low population densities. More rapid development at crowded sites brings clear advantages in intra-specific competition for the older instars. This response to increased nymphal population density is recorded for all the gerrids tested (Harada, 1996; Harada \& Spence, 2000; Harada et al., 1997 ) and is probably a general response shown by all Gerromorpha as suggested by Harada \& Spence (2000) for gerrids.

Individually reared nymphs developed fastest in both Mes. furcata and Micr. reticulata. They differ in this aspect from most orthopterans (Applebaum \& Heifetz, 1999). Two possible explanations of this phenomenon are proposed: (1) Rapid development of isolated specimens is advantageous in poor environmental conditions. Such conditions are probable if no other conspecifics are present. Rapid development shortens the juvenile period. Adults are more likely to search for mates and when there is little probability of meeting a mate as it is advantageous to reproduce as fast as possible. Finally, isolated nymphs do not waste energy competing for food or avoiding conspecifics. They can, therefore invest more energy into faster development. (2) The optimal nymphal population density in nature is probably close to the low population density treatment used in the experiments. High population density can be regarded as a form of environmental stress (Applebaum \& Heifetz, 1999). It is assumed that both high population density and isolation are stressful for the nymphs. Thus the fast development in the indi- 
vidual and high population density treatments may be a response to stressful conditions.

The second explanation is preferred because the first is based on the faster development of isolated nymphs being adaptive. However, isolated nymphs have (1) a low probability of completing development because it is highly likely the environmental conditions are poor. In the case of successful maturation, they have (2) a low probability of finding a mate. Finally, if isolated nymphs mature and find a conspecific population, (3) their potential to develop faster when isolated is unlikely to get fixed in the genofond of the functional population.

\section{Wing polymorphism}

The higher frequency of LW individuals recorded in response to rearing nymphs at a high population density in Mes. furcata is similar to that recorded for the gerrid species A. paludum (Harada et al., 1997) and veliids Micr. douglasi and Micr. horvathi (Muraji et al., 1989; Muraji \& Nakasuji, 1988). The LW specimens can leave crowded habitats and disperse to other sites. The closely related North American alary polymorphic species Mesovelia mulsanti produces LW, SW and WL morphs. SW individuals of this species have wings of variable length. They are referred to as "intermediate morphs" by Galbreath (1975). The main factor affecting wing development in Mes. mulsanti is probably temperature, but it has no significant effect on the development of the wings of the offspring of WL adults (Galbreath, 1975).

It is highly likely that the nymphs of Mes. furcata used in this study were offspring of WL parents. No LW adults of this species were found at the site from which the nymphs were collected for this study. The results indicate that a high nymphal population density can induce the development of the LW morph and thus an increase in the proportion of LW individuals, even in originally WL populations. Thus it is likely the following mechanisms of LW and SW morph induction occur in natural populations of this species: (1) temperature has a significant effect on the induction of LW and SW offspring only in alary polymorphic populations; (2) increased nymphal population density has a significant effect on the induction of LW and SW offspring respectively even in WL monomorphic populations. Such mechanisms are likely to be adaptive because it is unlikely that nymphs inhabiting large stable water bodies will become overcrowded because they are unlikely to dry out even when temperatures are high. Populations thus remain monomorphic WL and the main response to increased temperature is accelerated development. However, on small unstable water bodies, which are likely to dry out when temperature increases, the population density can reach a critical level and both LW and SW individuals can develop even in originally WL populations.

More LW individuals developed in $V$. caprai, but the effect was not significant. However, no LW adults of this species were found in the field, even at temporary sites. Given that Brönmark et al. (1985) record that $16 \%$ of the individuals in one abundant population in Sweden were LW, it is suggested that a high population density during nymphal development has little effect on the induction of long winged forms but changes in environmental / genetical factors could affect this response.

No changes in wing dimorphism in response to increased nymphal population density were observed in Micr. reticulata. This is similar to the response recorded for the gerrid G. pingreenensis (Harada \& Spence, 2000). Micr. reticulata differs in this respect from Micr. douglasi, Micr. horvathi and Micr. kyushuensis (see Muraji et al., 1989; Muraji \& Nakasuji, 1988). As the LW morph occurred at collecting sites, factors other than population density probably affect the development of the LW morph in this species.

In contrast, unpublished experiments carried out at the State University of Utrecht (The Netherlands) on Micr. reticulata some years ago revealed that wing polymorphism in this species is affected by nymphal population density. i.e., more LW specimens develop at higher population densities (Nico Nieser and Ping-ping Chen, pers. comm.). Andersen (1973) suggests that alary polymorphism was originally genetically determined in semiaquatic bugs and that environmentally induced alary polymorphism developed secondarily. In addition to "seasonal and environmental pterypolymorphism", genetically induced pterypolymorphism was also recorded in some species of Gerridae, e.g., the waterstrider Limnoporus canaliculatus (Calabrese, 1979; Vepsäläinen, 1974; Zera et al., 1983; Zera, 1991). The alary composition of the parental generation used in Utrecht experiments is unknown. But as mentioned above the males and females in the parental generation of Micr. reticulata in this study were all WL. Thus it is likely that the incidence of the gene(s) for LW differs between populations of this species.

On the other hand, several environmental factors influence wing dimorphism in various gerromorphan bugs. However, wing dimorphism is usually species specific and associated with the life history. For example, a long photoperiod (late spring conditions) induces a higher frequency of the LW morph in Micr. douglasi (Muraji et al., 1989). This species disperses in summer and overwinters close to the summer sites. As the mortality of LW individuals is higher than that of WL individuals in some species (Ahlroth et al., 1999), the lower proportion of winged individuals in the overwintering population could be adaptive. In contrast, photoperiod has the opposite effect on the wing dimorphism of most gerrids that migrate from breeding to overwintering sites (see Spence \& Andersen, 1994). There is a higher proportion of LW individuals in the overwintering generation.

It is thought that the reason why Gerris pingreenensis does not show alary dimorphism in response to population density is because this predominantly WL species inhabits permanent sites (Harada \& Spence, 2000). Like $G$. pingreenensis, Micr. reticulata colonizes permanent sites and the frequency of wing morphs is not influenced by nymphal population density. However, the percentage of LW individuals can be as much as $10 \%$ at some sites (T. Ditrich, unpubl. data). 
Individuals of $V$. caprai are almost always WL in Central European populations, regardless of the fact that this species usually occurs in both permanent and temporary habitats. Absence of the winged morph, even at crowded sites, may mean that dispersal by flight is not important in this species. Indeed, $V$. caprai disperses terrestrially (Ditrich \& Papáček, 2009a).

\section{Body size and rate of oogenesis}

The body size of the females of both Mes. furcata and Micr. reticulata are affected by nymphal population density as is the case in other gerrids (Harada \& Spence, 2000). The body length of Micr. reticulata females did not differ among treatments, but they had longer legs when reared at a high nymphal population density, which probably enables them to improve move faster on the water surface and increases their foraging success. The non-significant difference in leg length of males of Micr. reticulata recorded in this study may be due to the generally high variance in the length of male compared to female legs, as recorded for individuals of subsequent overlapping generations of Microvelia pulchella by Taylor \& McPherson (1999). It is assumed that both longer legs and a larger body size are advantageous. Surprisingly, these species did not show a trade-off between duration of nymphal development and body size, as has been reported for gerrids by Harada \& Spence (2000). Whereas gerrid nymphs reared at high population densities develop faster but produce small adults, the species in this study both developed faster at a high nymphal population density and produced larger adults than those developing at a low population density. The lack of a trade-off between body size and juvenile developmental time might be because there is a trade-off between the rate of growth of the gonads and duration of nymphal development. However, there is no evidence for such a trade-off in Mes. furcata because in this species the length of distal oocyte was similar in females reared at low and high nymphal population densities. However, as only eight females of Mes. furcata reached maturity in the high population density treatment, this trade-off might not be apparent because of the small sample size. Harada et al. (1997) record a slower development of ovaries in females reared at a high nymphal population density in $A$. paludum, but he did not provide the measurements of the individuals of this gerrid that were subjected to different treatments.

\section{CONCLUSIONS}

The population density at which the nymphs are reared has a marked affect on important life history traits such as wing polymorphism, body size and maturation of gonads in most gerromorphan bugs. However, even species in the same genus differ in their response to crowding. One of developmental patterns, generally common to gerromorphan bugs, is the effect of crowding on their rate of development: nymphs develop faster when reared at high than at low population densities. Nevertheless, specimens of Mes. furcata and Micr. reticulata reared individually have the highest developmental rates. Fast development occurs in response to stress in the form of either a very high or very low population density. In terms of body size, males show little response to being reared at different population densities. In contrast, females reared at both a high population density and individually are larger than those reared at a low population density. This response has been recorded in all the gerromorphan bugs studied. There is not a trade-off between body size and developmental rate in several water striders or the species tested in this study. By delaying gonad maturation individuals can achieve a larger body, even fast developing individuals. How species respond in terms of wing polymorphism to being reared at different population densities strongly depends on the life history of the species and cannot be generalized in the absence of ecological data.

ACKNOWLEDGEMENTS. The study was funded by a grant from the Grant Agency of the University of South Bohemia No. GAJU 6/2007/P-PrF and from the Ministry of Education, Youth and Sports of the Czech Republic No. MSM 6007665801. We are grateful to M. Krovová and V. Ditrich for help with maintaining and rearing the bugs, to T. Čermáková and E. Vojířová for help with the measurements and to D. Boukal, P. Štys and two unknown reviewers for valuable comments on the manuscript.

\section{REFERENCES}

Ahlroth P., Alatalo R.V., Hyvarinen E. \& Suhonen J. 1999: Geographical variation in wing polymorphism of the waterstrider Aquarius najas (Heteroptera, Gerridae). J. Evol. Biol. 12: $156-160$.

ANDERSEN N.M. 1973: Seasonal polymorphism and developmental changes in organs of flight and reproduction in bivoltine pondskaters (Hem. Gerridae). Entomol. Scand. 4: $1-20$.

Andersen N.M. 1982: The semiaquatic bugs (Hemiptera, Gerromorpha). Phylogeny, adaptations, biogeography, and classification. Entomonograph 3: 1-455.

Applebaum S.W. \& Heifetz Y. 1999: Density-dependent physiological phase in insects. Annu. Rev. Entomol. 44: 317-341.

Brönmark C., Malmqvist B. \& Otto C. 1985: Dynamics and structure of a Velia caprai (Heteroptera) population in a south Swedish stream. Holarct. Ecol. 8: 253-258.

Calabrese D.M. 1979: Pterygomorphism in 10 Nearctic species of Gerris. Am. Midl. Nat. 101: 61-68.

DAmGAARD J. 2008a: Evolution of the semi-aquatic bugs (Hemiptera: Heteroptera: Gerromorpha) with a re-interpretation of the fossil record. Acta Entomol. Mus. Nat. Pragae 48: 251-268.

DAmgaARd J. 2008b: Phylogeny of the semiaquatic bugs (Hemiptera: Heteroptera, Gerromorpha). Insect Syst. Evol. 39: 431-460.

Ditrich T. \& PAPÁČEK M. 2009a: Correlated traits for dispersal pattern: Terrestrial movement of the water cricket Velia caprai (Heteroptera: Gerromorpha: Veliidae). Eur. J. Entomol. 106: 551-555.

DitRICH T. \& PAPÁČEK M. 2009b: Effective strategy of the overwintering of semiaquatic bugs: overwintering of Velia caprai (Heteroptera: Gerromorpha: Veliidae). J. Nat. Hist. 43: 529-543.

Ditrich T., Papáček M. \& Broum T. 2008: Spatial distribution of semiaquatic bugs (Heteroptera: Gerromorpha) and their wing morphs in a small scale of the Pohořský Potok stream 
spring area (Novohradské Hory Mts.). Silva Gabreta 14: 173-178.

Galbreath J.E. 1975: Thoracic polymorphism in Mesovelia mulsanti (Hemiptera: Mesoveliidae). Univ. Kans. Sci. Bull. 50: $457-482$.

HARADA T. 1996: Effects of population density on the duration of nymphal period and diapause-posture at the adult stage in a water strider, Gerris latiabdominis (Hemiptera: Gerridae). Jpn. J. Entomol. 64: 413-419.

Harada T. \& Spence J.R. 2000: Nymphal density and life histories of two water striders (Hemiptera: Gerridae). Can. Entomol. 132: 353-363.

Harada T., Tabuchi R. \& Koura J. 1997: Migratory syndrome in the water strider Aquarius paludum (Heteroptera: Gerridae) reared in high versus low nymphal densities. Eur. J. Entomol. 94: 445-452.

MielewcZYK S. 1980: Zur Ökologie, Biologie und Morphologie von Velia saulii Tam. und V. caprai Tam. (Heteroptera, Veliidae). Ann. Zool. (Wars.) 35: 285-305.

Muraji M., Miura T. \& Nakasuji F. 1989: Phenological studies on the wing dimorphism of a semi-aquatic bug, Microvelia douglasi (Heteroptera, Veliidae). Res. Popul. Ecol. 31: $129-138$.

Muraji M. \& Nakasuji F. 1988: Comparative studies on lifehistory traits of three wing dimorphic water bugs, Microvelia spp Westwood (Heteroptera, Veliidae). Res. Popul. Ecol. 30: 315-327.

PAPÁČEK M. \& JANDOVÁ L. 2003: Extreme variability of life history in the water cricket Velia caprai, Tamanini 1947 (Heteroptera: Gerromorpha: Veliidae): the study under the environmental conditions of the Novohradské hory Mts. In Papáček M. (ed.): Biodiversity and Environmental Conditions of the Novohradské hory Mountains, University of South Bohemia and Institute of Entomology, Biology Centre, ASCR, České Budějovice, pp. 149-162 [in Czech, English abstr.]

Saulich A.H. \& Musolin D.I. 2007: Seasonal Development of Aquatic and Semiaquatic True Bugs (Heteroptera). St. Petersburg University Press, St. Petersburg, 205 pp.

Spence J.R. \& ANDERSEn N.M. 1994: Biology of water striders interactions between Systematics and Ecology. Annu. Rev. Entomol. 39: 101-128.

Stephens P.A., Sutherland W.J. \& Freckleton R.P. 1999: What is the Allee effect? Oikos 87: 185-190.

TAYLOR S.J. \& MCPhERSON J.E. 1999: Morphological variation and polyvoltinism of Microvelia pulchella (Heteroptera: Veliidae) in southern Illinois, USA. Acta Soc. Zool. Bohem. 63: $237-249$.

VEPSÄLÄINEN K. 1973: The distribution and habitats of Gerris Fabr. species (Heteroptera, Gerridae) in Finland. Ann. Zool. Fenn. 10: 419-444.

VEPSÄLÄINEN K. 1974: Determination of wing length and diapause in water-striders (Gerris Fabr., Heteroptera). Hereditas 77: $163-176$.

WróblewsKi A. 1980: Pluskawiaki (Heteroptera). Fauna stodkowodna polski. [True Bugs (Heteroptera). Freshwater Fauna of Poland]. Vol. 8. Państwowe Wydawnictwo Naukowe, Warszawa, Poznań, 154 pp.

ZERA A.J. 1991: Segregation and linkage analyse of five allozymes loci in Limnoporus canaliculatus. J. Hered. 82: 356-358.

Zera A.J., InNes D.J. \& SaKs M.E. 1983: Genetic and environmental determinants of wing polymorphism in the waterstrider Limnoporus canaliculatus. Evolution: 37: 513-522.

Zimmermann M. 1984: Population-structure, life-cycle and habitat of the pondweed bug Mesovelia furcata (Hemiptera, Mesoveliidae). Rev. Suisse Zool. 91: 1017-1035.

Received December 22, 2009; revised and accepted June 3, 2010 